\title{
Universiteit
}

Leiden

The Netherlands

\section{Neurosurgical Treatment Variation of Traumatic Brain Injury: \\ Evaluation of Acute Subdural Hematoma Management in Belgium and} The Netherlands

Essen, T.A. van; Ruiter, G.C.W. de; Kho, K.H.; Peul, W.C.

\section{Citation}

Essen, T. A. van, Ruiter, G. C. W. de, Kho, K. H., \& Peul, W. C. (2017). Neurosurgical Treatment Variation of Traumatic Brain Injury: Evaluation of Acute Subdural Hematoma Management in Belgium and The Netherlands. Journal Of Neurotrauma, 34(4), 881-889. doi:10.1089/neu.2016.4495

Version: $\quad$ Not Applicable (or Unknown)

License: $\quad$ Leiden University Non-exclusive license

Downloaded from: https://hdl.handle.net/1887/114780

Note: To cite this publication please use the final published version (if applicable). 


\title{
Neurosurgical Treatment Variation of Traumatic Brain Injury: Evaluation of Acute Subdural Hematoma Management in Belgium and The Netherlands
}

\author{
Thomas A. van Essen, ${ }^{1,2}$ Godard C.W. de Ruiter, Kuan H. Kho,, and Wilco C. Peul ${ }^{1,2}$
}

\begin{abstract}
Several recent global traumatic brain injury (TBI) initiatives rely on practice variation in diagnostic and treatment methods to answer effectiveness questions. One of these scientific dilemmas, the surgical management of the traumatic acute subdural hematoma (ASDH) might be variable among countries, among centers within countries, and even among neurosurgeons within a center, and hence be amenable for a comparative effectiveness study. The aim of our questionnaire, therefore, was to explore variations in treatment for ASDH among neurosurgeons in similar centers in a densely populated geographical area. An online questionnaire, involving treatment decisions on six case vignettes of ASDH, was sent to 93 neurosurgeons in The Netherlands and Belgium. Clinical and radiological variables differed per case. Sixty neurosurgeons filled out the questionnaire (response rate 65\%). For case vignettes with severe TBI and an ASDH, there was a modest variation in the decision to evacuate the hematoma and a large variation in the decision to combine the evacuation with a decompressive craniectomy. The main reasons for operating were "neurological condition" and "mass effect." For ASDH and mild/moderate TBI, there was large variation in the decision of whether to operate or not, whereas "hematoma size" was the predominant motivation for surgery. Significant inter-center variation for the decision to evacuate the hematoma was observed ( $p=0.01)$. Most pronounced was that 1 out of $7(14 \%)$ neurosurgeons in one region chose a surgical strategy compared with 9 out of $10(90 \%)$ in another region for the same scenario. In conclusion, variation exists in the neurosurgical management of TBI within an otherwise homogeneous setting. This variation supports the methodology of the international Collaborative European NeuroTrauma Effectiveness Research in Traumatic Brain Injury (CENTER-TBI) initiative, and shaped the Dutch Neurotraumatology Quality Registry (Net-QuRe) initiative.
\end{abstract}

Keywords: ASDH; TBI; treatment variation

\section{Introduction}

C URRENT AND FUTURE RESEARCH INITIATIVES in traumatic brain injury (TBI) aim to answer effectiveness questions using a comparative effectiveness approach. ${ }^{1}$ Whereas most traditional clinical trials have shown disappointing results as a result of methodological and ethical constraints, ${ }^{2,3}$ this comparative effectiveness methodological strategy seems promising for TBI, because considerable unexplained variation in outcome has been reported and hypothesized to be the result of variation in standard practice care. To relate the practice variation to the outcome variation, however, several of the hypothesized assumptions, imposed by the ambition to conduct effectiveness research using observational data, must be explored. Specifically, for many neurosurgical ef- fectiveness questions, mainly regarding severe TBI patients and/or patients with CT abnormalities, practice variation in care has to be present and be quantifiable in the data, while at the same time other factors (i.e., confounders) need to be uniformly distributed. Therefore, in preparation for the Dutch Neurotraumatology Quality Registry (Net-QuRe) and Collaborative European NeuroTrauma Effectiveness Research in Traumatic Brain Injury (CENTER-TBI) we aimed to explore with regard to one of the important neurosurgical questions, whether a detailed analysis would lead to a quantification of the hypothesized practice variation in an otherwise homogeneous area. The question entails the clinical dilemma of whether "to operate or not in acute subdural hematoma (ASDH)."

When confronted with a patient with TBI and an accompanying ASDH, (neuro)surgeons are faced with several management

\footnotetext{
${ }^{1}$ Neurosurgical Cooperative Holland, Department of Neurosurgery, Leiden University Medical Center, Leiden, The Netherlands.

${ }^{2}$ Neurosurgical Cooperative Holland, Department of Neurosurgery, Medical Center Haaglanden, The Hague, The Netherlands.

${ }^{3}$ Department of Neurosurgery, Medisch Spectrum Twente, Enschede, The Netherlands.

${ }^{4}$ Department of Neurosurgery, University Hospitals Leuven, Leuven, Belgium.
} 
dilemmas. The first and most challenging question is whether or not emergency surgery is indicated. The decision whether to evacuate an ASDH is based on a number of factors including the patient's age, Glasgow Coma Score (GCS), pupillary status, comorbidities, CT findings, and whether or not there is subsequent neurological deterioration. ${ }^{4}$ Prompt surgical evacuation can successfully decrease mortality, but it is also known that despite surgical and intensive care treatment, many patients die or have an unfavorable functional outcome. ${ }^{5-8}$ On the other hand, a substantial portion of patients managed conservatively may have long-term favorable outcomes. $^{9-11}$

The second question is whether evacuation of the hematoma should be accompanied by a bony decompression (a decompressive craniectomy [DC]). This decision seems to be mainly influenced by the following factors: observation of brain swelling during the surgery, intuitively expected secondary brain swelling by the treating clinicians (neurosurgeon, neurologist, or intensivist), medically intractable intracranial hypertension in the course of intensive care treatment, presence of penetrating (blast) brain injury, or simply, the hospital's protocol. ${ }^{4,12,13}$ The known complications of decompressive surgery have to be balanced against the risk of uncontrolled brain swelling. ${ }^{14,15}$

Ethical considerations complicate these decisions even more. Treatment decisions do not merely depend on efficacy based on mortality and functional outcome, but should also consider patient autonomy and incorporate perceived cognitive and somatic disability. Evacuation of the hematoma can be life-saving, but at the same time may lead to survival of a patient with a poor quality of life (QoL) or even absence of autonomous cognitive functioning and rational thinking. ${ }^{16,17}$

In addition, these complicated decisions often have to be made in far from ideal conditions, constrained by time, and with incomplete information of patients' medical history. And because of the 24/7 occurrence of these traumas, often at difficult moments, such as in the middle of the night or on a weekend when regular consultation between senior staff and colleagues is difficult, important treatment choices frequently have to be made by one medical expert, mostly the neurosurgeon on call.

Society, and, therefore future patients in particular, will have the opinion that these difficult decisions in TBI management follow protocolled schemes and algorithms, thereby excluding doubt. The contrary of this assumption might, however, be more accurate. Surgical decision making is hampered by the lack of evidencebased selection criteria as a consequence of the absence of robust scientific grounds for surgical indications. ${ }^{18}$ The most recent and most broadly known guidelines, The Brain Trauma Foundation (BTF) guidelines on the surgical management of $\mathrm{ASDH}^{4}$ are deduced from studies with a maximum of level 3 evidence. Since then, the only study exceeding this level ${ }^{19}$ has also not led to clearly defined surgical indications for procedures for patients with an ASDH. Generally, in TBI, there is a lack of high quality evidence relating surgery to outcome, mostly as a result of methodological constraints. $^{20,21}$

Therefore, confronted with a patient with a traumatic ASDH, clinicians have to deal with multiple clinical and radiological variables, in a very limited time frame and with a shortage of data or predictive outcomes. In this setting, the training background of the trauma team, the culture of the way treatment is being performed in that particular hospital, and the intuition of the neurosurgeon on call could be the most important factors that predict surgical decisions. How this echoes into current practice patterns with possibly variation in TBI management protocols has been scarcely investigated.
Hypothetically, no large difference in background and university training of neurosurgeons exists in Belgium and The Netherlands and, therefore, a low practice variation is to be expected. So far, no study has evaluated if this varying trauma management could also be the result of a variable view among neurosurgeons.

Therefore, we performed an online questionnaire study with questions on the clinical management of hypothetical cases, based on real patients with an ASDH, to determine whether variability in view exists among neurosurgeons on treatment of the ASDH, and which potential factors might influence surgical decision making, by presenting cases that varied with regard to the patient's age, severity (in GCS), thickness of the hematoma, and mass effect. The study was conducted in this area with the global goal of evaluating the differences in healthcare provider profiles in a hypothetically homogeneous area.

\section{Methods}

The Netherlands and Belgium are small countries with high population densities. Neurosurgical care for patients with TBI is provided at 11 level I trauma centers, serving separate areas according to regional referral policies. Acute trauma care is uniformly organized for all patients, with equal distribution of resources among hospitals. Almost all inhabitants (97.7\%) are within $30 \mathrm{~min}$ reach from a trauma center (Fig. 1).

Regular day-to-day cases with TBI and CT brain abnormalities suspected of ASDH were selected. The medical history and CT scans of these patients with traumatic ASDH were retrieved from the medical records of Leiden University Medical Center, Medical Center Haaglanden, and University Hospitals Leuven. We reviewed these cases and selected six cases, based on individual variability among patients, with different medical histories, based on severity, age, and duration between the accident and presentation to the hospital (Fig. 2). In order to examine potential variation in treatment, we selected four cases that evoked discussion a priori

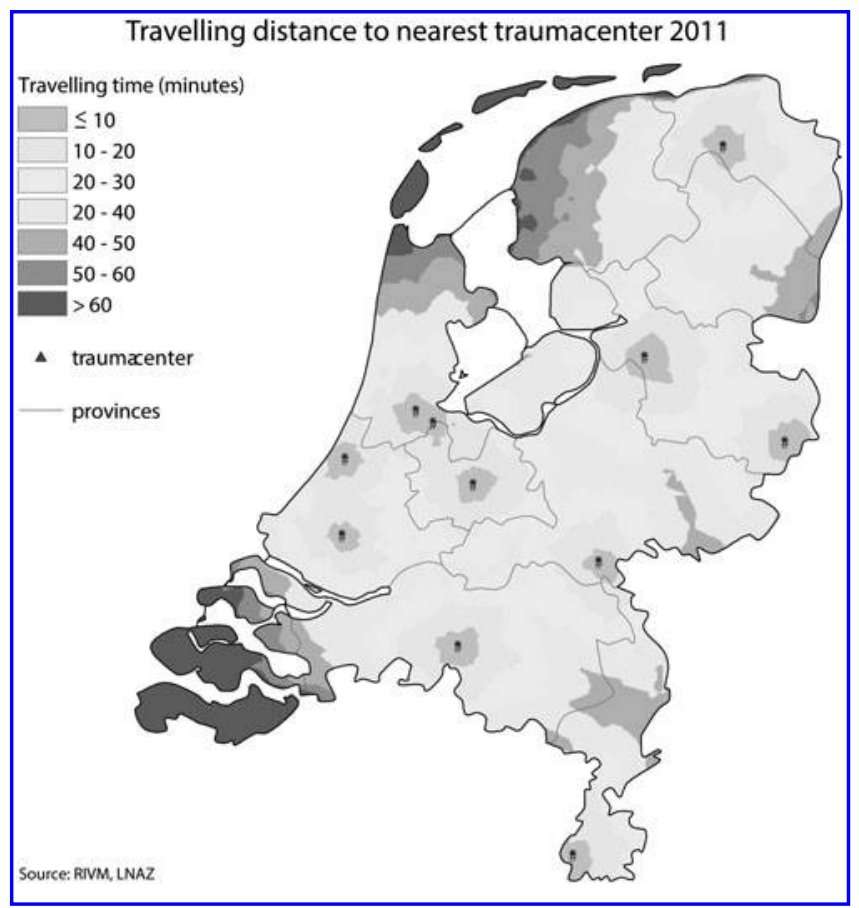

FIG. 1. Average traveling time to a trauma center in the Netherlands. 


\section{Case 1}

Woman, 27 years, motor vehicle accident half hour ago, fall on right side of head.

History: blank. Medication: none.

Neurological exam

E3M5V1, localizes with right arm, not with left arm.

Cranial nerves: normal pupillary reactivity and corneal reflex on both sides.

$C T$

Left-sided ASDH, contusions left frontotemporal, impression fracture petrous bone right.

Midline shift $1 \mathrm{~cm}$ to the right. Obliterated basal cisterns.

Case 2

Man, 28 years, assault 40 minutes ago, GCS of E1M2V2 and normal pupillary reactivity both sides.

History: unknown. Medication: unknown.

Neurological exam

E1M2V2, no lateralization. Cranial nerves: normal pupillary reactivity on both sides. CT

Left-sided ASDH, severe midline shift to the right.

\section{Case 3}

Man, 72 years, found unconscious, unclear since when.

History: atrial fibrillation. Medication: acenocoumarol.

Neurological exam

E1M2V1. Cranial nerves: pupil anisocoria (left > right), left pupil nonreactive, normal corneal and oculocephalic reflexes.

Blood results

INR 3,6

CT

Large left -sided ASDH with severe midline shift.

\section{Case 4}

Man, 79 years, fall on head couple of hours ago. History: diabetes mellitus and hypertension.

Medication: no anticoagulants, no aspirin.

Neurological exam

E3M6V5. Cranial nerves: no abnormalities.

Motor function: paretic right arm (MRC 4), no other paresis.

$C T$

Left-sided ASDH of $20 \mathrm{~mm}$. Midline shift $9 \mathrm{~mm}$. Normal basal cisterns.

\section{Case 5}

Man, 43 years, assault 2 days ago, headache since then, today nausea and vomiting, no loss of consciousness.

History: aorta insufficiency grade 1 - 2, atrial fibrillation. Medication: acenocoumarol. Neurological exam

EMV 15. No aphasia. Cranial nerves: normal. Motor function: slight drifting right arm (Barré).

Blood results

INR 2.36.

$C T$

Left-sided ASDH of $10 \mathrm{~mm}$, midline shift of $5 \mathrm{~mm}$.

\section{Case 6}

Woman, 79 years, motor vehicle accident, remembers everything, mild headache without other symptoms.

History: Percutaneous coronary intervention. Medication: aspirin.

Neurological exam

Wound on back of head.

EMV15. No abnormalities.

$C T$

Left-sided ASDH with mild midline shift to the right. Fracture line caudal side of maxillary sinus.

FIG. 2. The six case vignettes and the accompanying CT scans 


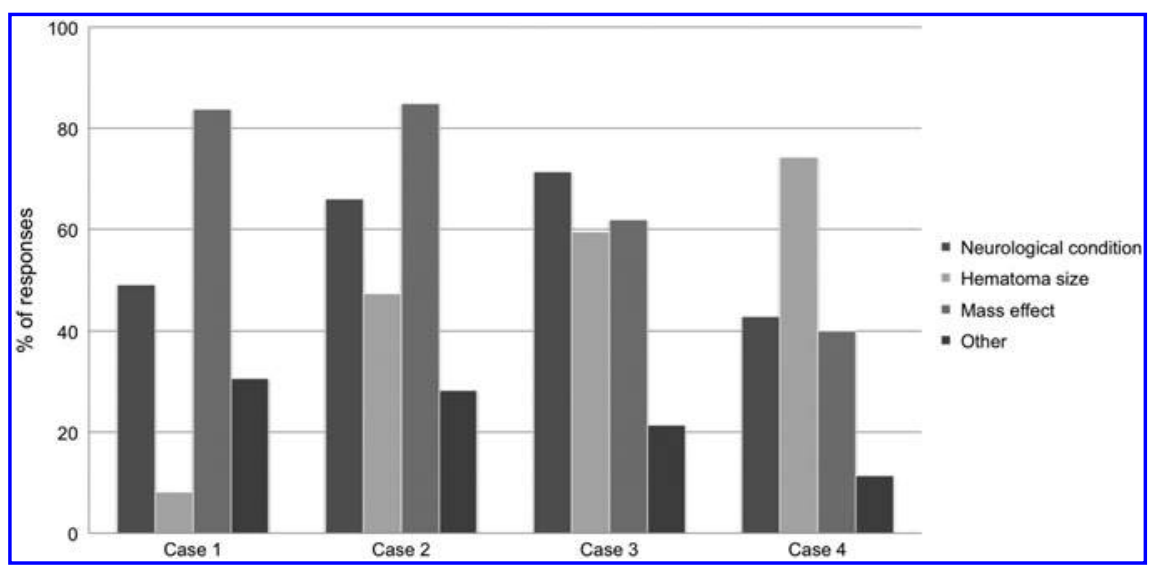

FIG. 3. Graph illustrating the reason(s) for evacuation of the acute subdural hematoma, in percentages of responses (proportions). The respondents had the choice to give multiple answers per case. Cases 5 and 6 were not included, because a minority of surgeons chose to operate (see Table 1). The numbered cases refer to the cases shown in Figure 2.

in the author group and two cases that did not (as a control group). Cases 1, 2 (control), and 3 represented severe and moderate TBI; that is, GCS 3-12, and cases 4, 5 (control), and 6 represented mild TBI; that is, GCS 13-15. The cases were presented in a fixed random order (i.e., equal for every respondent). The provided information per case consisted of the clinical characteristics depicted in Figure 2 and three axial CT coupes (one of which is shown in the figure). In Table 1 the questions regarding these cases are listed.

Dutch and Belgian neurosurgical department chiefs were asked by email whether we could send them a survey on operative management of the traumatic ASDH to their staff members. An invitation for the online questionnaire was subsequently sent to the staff clinicians, fellows, and chief residents working in the responding neurosurgical departments. The online survey was made and disseminated using the web survey tool SurveyMonkey (SurveyMonkey Inc., Palo Alto, CA, www. surveymonkey.com).

Collected variables for the neurosurgeon were age, location of residency program, current clinical department, and practicing time (time since finishing residency). The various treatment options were analyzed for each case in general (all neurosurgeons). Whether the responders would have operated or not was also analyzed per center (or geographical region) if more than half of the employed staff clinicians responded. The question of whether to combine the evacuation with a decompressive procedure was also regionally analyzed, but only for the severe TBI cases $(1,2$, and 3$)$

Table 1. Questions, Possible Answers, and Responses (Proportions) with Regard to the Clinical Case Vignettes

\begin{tabular}{|c|c|c|c|c|c|c|c|}
\hline \multirow[b]{2}{*}{ Questions } & \multirow[b]{2}{*}{ Possible answers } & \multicolumn{6}{|c|}{ Answers (\%) } \\
\hline & & Case 1 & Case 2 & Case 3 & Case 4 & Case 5 & Case 6 \\
\hline \multirow{2}{*}{$\begin{array}{l}\text { 1. Would you perform an operation } \\
\text { on this patient? }\end{array}$} & Yes & $53(88.3)$ & $60(100)$ & $46(76.7)$ & $41(68.3)$ & $3(5.0)$ & $3(5.0)$ \\
\hline & No & 7 (11.7) & 0 & $14(23.3)$ & $19(31.7)$ & $57(95)$ & $57(95)$ \\
\hline \multirow{2}{*}{$\begin{array}{l}\text { 2. Would you be willing to leave } \\
\text { this decision (whether to operate } \\
\text { or not) open for randomization } \\
\text { in a study? }\end{array}$} & Yes & $14(23.3)$ & $5(8.3)$ & $17(28.3)$ & $29(48.3)$ & $24(40)$ & $12(20)$ \\
\hline & No & $45(75)^{\mathrm{a}}$ & $55(91.7)$ & $43(71.7)$ & $31(51.7)$ & $36(60)$ & $48(80)$ \\
\hline \multirow[t]{4}{*}{$\begin{array}{l}\text { 3. If you answered "yes" to Q1, } \\
\text { what kind of operation would } \\
\text { you perform? }\end{array}$} & $\begin{array}{l}\text { a) Craniotomy with } \\
\text { evacuation } \\
\text { of the hematoma }\end{array}$ & $5(9.4)$ & $14(23.3)$ & $35(76.1)$ & $39(95.1)$ & $2(66.7)$ & $2(66.7)$ \\
\hline & $\begin{array}{l}\text { b) DC with evacuation } \\
\text { of the hematoma }\end{array}$ & $39(73.5)$ & $40(66.7)$ & $8(17.4)$ & 0 & 0 & 0 \\
\hline & c) Burr hole drainage & 0 & 0 & 0 & 0 & 0 & \\
\hline & $\begin{array}{l}\text { d) Another option, } \\
\text { please specifyb }\end{array}$ & $5(9.4)$ & $6(10.0)$ & $2(4.3)$ & $2(4.9)$ & $1(33.3)$ & $1(33.3)$ \\
\hline \multirow{3}{*}{$\begin{array}{l}\text { 4. Would you place an ICP } \\
\text { sensor? }\end{array}$} & Yes & $43(71.7)$ & 49 (81.7) & $26(43.3)$ & $3(5.0)$ & 0 & 0 \\
\hline & No & $6(10)$ & $10(16.7)$ & $31(51.7)$ & $56(93.3)$ & 55 (91.7) & $55(91.7)$ \\
\hline & $\begin{array}{l}\text { Depends on } \\
\text { intraoperative } \\
\text { swelling }\end{array}$ & $8(13.3)^{\mathrm{a}}$ & $0^{\mathrm{a}}$ & $0^{\mathrm{a}}$ & $0^{\mathrm{a}}$ & $0^{\mathrm{a}}$ & $0^{*}$ \\
\hline
\end{tabular}

\footnotetext{
${ }^{\mathrm{a}}$ Numbers do not add up because some respondents did not answer.

${ }^{\mathrm{b}}$ For cases 1, 2 and 3, the respondents answered that they would perform a decompressive craniectomy dependent upon intraoperative swelling. For cases 4,5 , and 6 the respondents would start dexamethasone and/or would perform a burr hole drainage at a later stage.

DC, decompressive craniectomy; ICP, intracranial pressure.
} 


\section{Statistical analysis}

Because the outline of this study was descriptive, only a few statistical analyses were employed. Statistical comparisons were limited to the analysis of regional variation using the $\chi^{2}$ test and Fisher's exact test when appropriate. For statistical analysis, SPSS 20.0 (IBM, Chicago, Il, USA) was used. $P$ values $<0.05$ were considered of statistical significance. The missing values (unanswered questions) for all questions were accepted up to $4 \%$ for all questions. Missing data were left out, and observed data were analyzed unless stated otherwise.

\section{Results}

\section{Neurosurgeon's characteristics}

The survey was completed by 60 respondents ( 53 neurosurgeons and 7 chief residents) out of a total of 93 invitations sent out (response rate $65 \%$ ). Of the respondents, 43 work in the Netherlands and 17 in Belgium. The responding neurosurgeons work in, respectively, Amsterdam, Enschede, Leiden/The Hague, Nijmegen, Rotterdam, Tilburg, Antwerp, Brussels, or Leuven. Three clinicians did not report their center. The number of clinicians per center is kept anonymous. The respondents had a mean age of 44 years (range 30-67) with a median time since finishing residency of 12 years (Table 2).

\section{Strategy for patients with severe $T B I$ and $A S D H$}

For patients with severe TBI and ASDH (cases 1, 2, and 3) there was variation in the decision to surgically evacuate the hematoma or not; respectively $88 \%, 100 \%$, and $77 \%$ answered "yes" to the question "would you operate or not?" and $23 \%, 8.3 \%$, and $28 \%$, respectively, answered "yes" to the question "randomize or not?" (Table 1). The question "DC or not?" resulted in, respectively, $74 \%, 67 \%$, and $17 \%$ anwering "yes," indicating variation in type of surgery per case. In addition, respectively, five $(9.4 \%)$, six $(10 \%)$, and two $(4.3 \%)$ would choose to perform a DC intraoperatively only when the brain was considered to be swollen. For all other neurosurgeons, a craniotomy was the preferred strategy. For the question "intracranial pressure [ICP] measurement?" respectively, $72 \%, 82 \%$, and $43 \%$ of neurosurgeons answered "yes." For case 1, all other neurosurgeons answered "no," except for eight neurosurgeons (13\%) who chose to place an ICP monitor dependent upon intraoperative brain swelling. For cases 2 and 3, all other neurosurgeons did not choose to place an ICP sensor.

\section{Strategy for patients with mild TBI and ASDH}

For the patients with mild TBI and ASDH (cases 4, 5, and 6) there is considerable variation in the decision to surgically evacuate the hematoma or not (Table 1; “'operate or not?” respectively, $68 \%$,

Table 2. Baseline Characteristics

\begin{tabular}{lc} 
Responder's characteristics & Number of responders (\%) \\
\hline Number of responders & 60 of $93(65)$ \\
Male & $55(92)$ \\
Dutch & $43(72)$ \\
Age & 44, range $30-67$ \\
Chief residents in neurosurgery & $7(12)$ \\
Years since finishing residency & $12,14 \mathrm{IQR}$ \\
\hline
\end{tabular}

$\mathrm{IQR}$, interquartile range.
Table 3. The Relationship between the Neurosurgeon's Age and Tendency to Operate

\begin{tabular}{lccc}
\hline & \multicolumn{3}{c}{ Age } \\
\cline { 2 - 4 } $\begin{array}{l}\text { Hypothetically } \\
\text { operated }(\%)\end{array}$ & $\leq 45$ yrs & $>45 y r s$ & $\mathrm{p}$ \\
\hline Case 1 & $31(93.9)$ & $18(81.8)$ & 0.20 \\
Case 2 & $33(100)$ & $22(100)$ & N/A \\
Case 3 & $23(69.7)$ & $18(81.8)$ & 0.31 \\
Case 4 & $20(60.6)$ & $17(77.3)$ & 0.19 \\
Case 5 & $2(6.1)$ & $1(4.5)$ & 1.0 \\
Case 6 & $2(6.1)$ & $0(0.0)$ & 0.51 \\
Total & $111(56.1)$ & $76(57.5)$ & 0.80 \\
\hline
\end{tabular}

Five respondents did not report their ages.

$5.0 \%$, and $5.0 \%$ "yes" answers; positive incentive for randomization, respectively, $48 \%, 40 \%$, and $20 \%$ ). DC was never chosen in mild cases. ICP measurement was chosen in three mild TBI cases (5.0\% for case 4$)$.

\section{Indications for surgery}

For cases with severe TBI, the main reasons for surgery for the ASDH were "neurological condition" and "mass effect." For the operated mild TBI case, "hematoma size" was the most important variable for the decision to operate (Fig. 3).

\section{Age and practice variation}

There was no association between age and tendency to operate for any of the six cases individually or overall (Table 3 ).

\section{Regional variation}

Region was associated with the decision to evacuate the hematoma or not (Table 4). For case 1, the proportion of surgical strategies did not differ among regions. For case 3, neurosurgeons in regions $\mathrm{A}$ and $\mathrm{B}$ were less aggressive, although not significantly, with regard to evacuating the hematoma, than those in regions $\mathrm{C}, \mathrm{D}$, and E. For case 4, there was a significant association between region and the decision whether to operate or not. Most notably, 1 out of $7(14 \%)$ of neurosurgeons in one region chose a surgical strategy compared with 9 out of $10(90 \%)$ in another region for this case vignette. The intra-center variability, that is, among neurosurgeons within a center, was most pronounced for region $\mathrm{B}$, as can also be deduced from Table 4. Lastly, there seemed to be a moderate regional variation for the decision to combine the primary evacuation of the hematoma directly with a DC: in case one $57 \%$ of region B $(n=7)$ would perform a primary DC compared with $100 \%$ of region $\mathrm{C}(n=16)$.

\section{Discussion}

Remarkably, and in contrast to the authors' hypothesis, this study suggests that standard treatment of (severe) TBI is highly variable because of a differing view on neurosurgical management despite the small size of the countries studied, dense population, and similar training curricula of trauma team physicians.

The survey results show that surgical decision making for patients with ASDH varies considerably in the Dutch-speaking part of The Netherlands and Belgium. Practice variation in the treatment of ASDH among countries and within large countries such as the United States is probable, but was not suspected within small 
Table 4. The Relation between Region and Tendency To Operate

\begin{tabular}{|c|c|c|c|c|c|c|}
\hline \multirow{2}{*}{$\begin{array}{l}\text { Hypothetically } \\
\text { operated }(\%)\end{array}$} & \multicolumn{6}{|c|}{ Regions } \\
\hline & $A(\mathrm{n}=3)$ & $B(\mathrm{n}=7)$ & $C(\mathrm{n}=16)$ & $D(\mathrm{n}=10)$ & $E(\mathrm{n}=7)$ & $\mathrm{p}$ \\
\hline Case 1 & $2(66.7)$ & $6(85.7)$ & $14(87.5)$ & $10(100)$ & $85.7(6)$ & 0.49 \\
\hline Case 3 & $1(33.3)$ & $3(42.9)$ & $14(87.5)$ & $9(90)$ & 7 (100) & 0.17 \\
\hline Case 4 & $0(0)$ & $1(14.3)$ & $13(81.2)$ & $9(90)$ & $6(85.7)$ & 0.01 \\
\hline
\end{tabular}

countries among hospitals or even among neurosurgeons. The variation in neurosurgical management among regions and among neurosurgeons is quite impressive, and cannot be explained by the lack of evidence alone. Ethical considerations, that is, personal opinions about value of a meaningful life from a humanistic perspective, probably play an important role. It could be true that the reasons and predictions of clinicians in charge of TBI patients, driving life and death decisions, and, similarly, how well a neurosurgeon or neurologist can actually predict the outcome, have a profound impact on the prognosis of TBI patients. Therefore, we feel that the different treatment strategies, reflected by the differing opinions in this study, should be related to the true outcome, which can best be challenged by a comparative observational study of the different strategies with a comprehensive assessment of the longterm outcome (CENTER-TBI and Net-QuRe).

Specifically, this study shows that there seem to be two groups of TBI-ASDH patients that pose a challenging problem in surgical decision making, namely 1) patients with slight decrease in consciousness, that is, mild TBI, combined with a large hematoma, and 2) elderly patients with a seemingly poor prognostic profile. These two groups will be discussed separately. A most remarkable finding was the regional variation (Table 4), which forms an important basis for future research on this subject and will be discussed subsequently.

\section{Mild symptoms but large ASDH}

The patients with a slight decrease in consciousness and a large ASDH (thickness $>10 \mathrm{~mm}$ ), such as case 4 , appear to be a clinical challenge, because there was a broad variation in the decision whether to operate or not, as well as a high incentive to randomize. Presumably, neurosurgeons in favor of evacuation of the subdural hematoma estimate that acting too slowly when there is a large ASDH leads to neurological deterioration or death. Their suspicion is backed by the BTF guideline, which was devised in 2005 by an international panel of experts, which states that every ASDH with a thickness $>10 \mathrm{~mm}$ and a midline shift over $5 \mathrm{~mm}$ should be evacuated as soon as possible, irrespective of neurological condition. ${ }^{4}$ On the other hand, surgeons in favor of a conservative strategy do not want to expose the patient to the risks of a craniotomy without a more precise estimation of the chance of neurological deterioration when withholding an operation. It can be argued that the guideline and the evidence so far should not guide treatment, because good quality comparative studies are lacking. Specifically, the reviewed studies of the BTF guideline were of a low level of evidence, were retrospective, used small or selected study populations, and had been performed $>10$ years earlier. Since then, the only study exceeding this level is an Austrian prognostic study. ${ }^{19}$ Unfortunately, this study included patients with an ASDH caused by severe TBI, whereas patients with an ASDH caused by mild or moderate TBI were not analyzed. This group represents up to $54 \%$ of patients with an $\mathrm{ASDH} .{ }^{9}$ Consequently, these results have not led to a clearly defined subset of surgical indications for procedures for patients with an ASDH.

\section{Elderly patients with a poor prognosis}

The second category of ASDH patients that forms a clinical dilemma is the prognostically unfavorable group of the elderly patient with severe TBI (as presented in case 3). Importantly, this clinical dilemma will only become more relevant, because the number of elderly patients with a TBI is rapidly increasing ${ }^{22}$ and, specifically, because subdural hematomas are more frequent in older patients. $^{23}$

Treating neurosurgeons choose not to operate because they believe that the outcome will still be unfavorable if they operate. On the other hand, the reason to perform surgery could be that a neurosurgeon believes that every patient deserves a chance to survive, however unlikely that may be. This tendency to act in severe TBI cases especially concerns young patients. In elderly patients, some neurosurgeons are more reserved, and abstain from cranial surgery, as is illustrated in case 3 , probably because of an estimated poor prognosis. To understand the variation in surgical decision making is to understand the different metrics used to objectify the outcome of patients. Clearly, the estimation of an unfavorable outcome or prognosis critically depends upon how a worthwhile outcome is valued according to the treating neurosurgeon, trauma surgeon, intensivist, or neurologist. Although functional outcome scales are generally used to determine effectiveness in neurotraumatology studies (i.e., the extended Glasgow Outcome Scale [GOSE]), neurosurgeons might consider other factors in the clinical setting. Often the conceptual issue QoL is routinely employed in clinical setting, especially in talking about the expected outcome of patients with a severe TBI. The neurosurgeon might estimate that the life that will be saved is not worth living or will result in a low QoL, and, therefore, an evacuation is not performed.

In this context, it is interesting to see how a validated QoL instrument performs in ASDH patients. Therefore, we performed a 4 year cohort study in Leiden and The Hague in which it was shown that ASDH patients with a presenting GCS $>12$ do not differ in their long term QoL (as measured by the Qolibri scale ${ }^{24,25}$ ) from surviving ASDH patients with a presenting GCS $<9 .^{26}$ This finding relates to the disability paradox, in which patients with severe disease or disability do not necessarily report a poor QoL. ${ }^{27}$

\section{Surgical decision making in ASDH}

Making decisions under uncertainty, especially when time constrained, as is the case with patients with traumatic ASDH, is susceptible to bias, ${ }^{28}$ and, therefore, can lead to practice variation. Analyzing the factors associated with this variation will let us understand how the decisions are made and can be improved. The challenges in understanding surgical decision making have been described for patients with spontaneous intracerebral hemorrhage. ${ }^{29}$ 
Each of these issues can also more or less hamper surgical decision making in traumatic ASDH. Explicitly, in this investigation, evidence is found for region as an important aggregating factor for the variation in surgical care. The most likely explanation for this result is a differing practice culture among institutions and difference in the training backgrounds of neurosurgeons.

Also, we will elaborate on a possible explanation for the discrepancy in the presented variation between severe and mild cases. There was a higher positive incentive for randomization in cases with mild symptomatology $(4,5$, and 6$)$ than in severe cases $(1,2$, and 3), possibly reflecting more uncertainty with regard to mild/ moderate TBI and ASDH. However, although the percentages of "yesses" for surgery in cases 1, 2, and 3 were relatively high, it is important to realize that variation exists even for severe neurotrauma cases, in which the decision of whether to operate or not often is a matter of life or death. An important explanation could be that neurosurgeons are more convinced of the merits of rapid surgical evacuation in severe cases. In part this might also be explained by a human instinct to act or do something for a patient with a lifethreatening condition.

\section{Regional variation in the literature}

Although no similar survey has been conducted, other studies have shown that variability in treatment of TBI exists. Rayan and coworkers showed that in only $17 \%$ of a random sample of (brain) trauma patients was care delivered according to the BTF guidelines, ${ }^{30}$ suggesting a variable approach. In addition, in an international survey, it was shown that there was a difference in point of view among neurosurgeons with respect to combining the evacuation of an ASDH with a DC. ${ }^{31}$ Furthermore, inter-center variation in TBI has been shown to exist for referral policy, admission organization, and intensive care management (including ICP treatment). ${ }^{32-38}$

The intercenter or regional variation in surgical treatment of ASDH has not been shown in the literature. For other lifethreatening or emergency disorders it has been investigated and confirmed for the ruptured abdominal aneurysm ${ }^{39}$ and the spontaneous intracerebral hemorrhage. ${ }^{40}$

\section{Strengths and limitations of the study}

The main strength of our study is the standardized manner of the questionnaire that was submitted to medical professionals. Although the senior authors (GdR, KHK, WCP) had a strong belief in homogeneous results across neurosurgeons and regions, the study subjects did choose quite different options for the same patient. In the aforementioned studies on current practices in TBI management, variation can be explained by other factors; for example, by different institutional infrastructure or resources, by divergent patient preferences, or by case mix.

In addition, for the first time, the pivotal clinical dilemma of whether "to operate or not" is addressed, because case vignettes are presented across the whole spectrum of TBI (GCS 3-15). Other studies focus on how care is provided for certain patient subgroups; that is, those with large ASDHs and/or severe TBI. Hence, the main approaches that are evaluated involve managing high ICP with DC. ${ }^{31,41}$ Therefore, our study provides insight into real-life situations in which neurosurgeons are confronted by ASDH patients with heterogeneous clinical and radiological factors.

A very important but inevitable limitation of this study is its setup as a survey, wherein the actual real-life clinical setting is lacking. In the clinical setting, the studied decisions often have to be made in far from ideal circumstances, with potentially fatal consequences. In contrast, the decisions in this questionnaire are purely complicated by patient characteristics. Nonetheless, although it is acknowledged that this lack of real-life conditions could influence every respondent differently, the main conclusion about variation in ASDH management is most likely justified.

\section{Future direction: Comparative effectiveness research (CER)}

An explanation for the apparent lack of a high level of evidence for surgical management for TBI is the difficulty of performing randomized clinical trials. Generally in TBI research, the heterogeneous study population of TBI; that is, the multitude of patient characteristics and treatment variables, together with small patient numbers, make powering clinical trials problemat$\mathrm{ic}^{21}$ and, therefore, requires an extensive investment of time and money. Specifically for efficacy research of surgical strategies, randomizing surgical treatments for TBI is difficult to perform because of the ethical concerns of withholding a potentially lifesaving procedure. In the presented study, this is reflected in the low motivation to randomize severe TBI cases. And even if a trial succeeds, it regularly has limited external validity, because the treatment effect has been evaluated in certain subgroups, with management protocols that are sometimes difficult to replicate in the whole population. The randomized controlled trials (RCT) on the surgical treatment of TBI, the Decompressive Craniectomy in Patients with Severe Traumatic Brain Injury (DECRA) study ${ }^{15}$ and the Surgical Trial in Traumatic Intracerebral Haemorrhage (STITCH-Trauma) $^{42}$ trial are examples illustrative of these methodological difficulties.

Because of these methodological challenges, the focus of much TBI research in the last decades has been on suggestions for optimizing RCT design and new study designs in TBI. ${ }^{2,3}$ A promising approach could be the so-called "comparative effectiveness research" (CER). In this design, the heterogeneity and variability, which trouble RCT, are accepted and exploited to study the effectiveness of treatments as they occur in real-life practice. This CER analysis of (surgical) treatment for TBI is currently one of the goals of a Dutch initiative called Net-QuRe and an international research initiative called CENTER-TBI of which the authors are scientific participants (www.center-tbi.eu). The natural existing variation in management shown in this questionnaire provides a strong incentive for such a pragmatic observational study in which the variation in surgical strategies is compared among regions and/ or neurosurgeons. The rationale for this effort is further strengthened by the fact that the variability in the field of TBI management goes alongside unexplained variability in outcome. In a study by Lingsma and colleagues, ${ }^{43}$ more than threefold differences were found in the probability over and above chance effects to have an unfavorable outcome among the centers, which could not be explained by adjustments for the most important predictors of outcome in TBI (age, GCS motor score, and pupil reactivity). Hence, relating this unexplained variation in outcome to the current practice variation is a promising methodological strategy in the challenging field of TBI research. ${ }^{2,44}$

There is a large variation in management approach for the traumatic ASDH in a medically uniformly trained European region: The Netherlands and Belgium. Interestingly, there was a regional variation in a surgical versus conservative approach. Ultimately, this variation in management should be exploited in a comparative effectiveness study. 


\section{Acknowledgments}

The authors thank Dr. Johannes Van Loon and Prof. dr. Bart Depreitere (neurosurgeons, Department of Neurosurgery, University Hospitals Leuven, Leuven, Belgium) for their involvement in case selection, all Dutch and Belgian neurosurgeons who participated in filling out the questionnaire, and Dr. Carmen L. Vleggeert-Lankamp (neurosurgeon, Department of Neurosurgery, Leiden University Medical Center, Leiden, The Netherlands) for critical appraisal of the first draft of our manuscript. This work was supported by The European Union seventh Framework Program (grant 602150) for Collaborative European NeuroTrauma Effectiveness Research in Traumatic Brain Injury (CENTER-TBI) and Hersenstichting Nederland (Dutch Brain Foundation) for Neurotraumatology Quality Registry (Net-QuRe).

Portions of this work were presented at the 11th Symposium of the International Neurotrauma Society, Budapest, Hungary, March 19-23, 2014.

\section{Author Disclosure Statement}

No competing financial interests exist.

\section{References}

1. Maas, A.I.R., Menon, D.K., Steyerberg, E.W., Citerio, G., Lecky, F., Manley, G.T., Hill, S., Legrand, V., and Sorgner, A. (2015). Collaborative European NeuroTrauma Effectiveness Research in Traumatic Brain Injury (CENTER-TBI): a prospective longitudinal observational study. Neurosurgery 76, 67-80.

2. Maas, A.I.R., Menon, D.K., Lingsma, H.F., Pineda, J.A., Sandel, M.E., and Manley, G.T. (2012). Re-Orientation of clinical research in traumatic brain injury: report of an international workshop on comparative effectiveness research. J. Neurotrauma 29, 32-46.

3. Tosetti, P., Hicks, R.R., Theriault, E., Phillips, A., Koroshetz, W., and Draghia-Akli, R. (2013). Toward an international initiative for traumatic brain injury research. J. Neurotrauma 30, 1211-1222.

4. Bullock, M.R., Chesnut, R., Ghajar, J., Gordon, D., Hartl, R., Newell, D.W., Servadei, F., Walters, B.C., and Wilberger, J.E. (2006). Surgical management of acute subdural hematomas. Neurosurgery 58, S16-24.

5. Tallon, J.M., Ackroyd-Stolarz, S., Karim, S.A., and Clarke, D.B. (2008). The epidemiology of surgically treated acute subdural and epidural hematomas in patients with head injuries: a population-based study. Can. J. Surg. 51, 339-345.

6. Li, L.M., Kolias, A.G., Guilfoyle, M.R., Timofeev, I., Corteen, E.A., Pickard, J.D., Menon, D.K., Kirkpatrick, P.J., and Hutchinson, P.J. (2012). Outcome following evacuation of acute subdural haematomas: a comparison of craniotomy with decompressive craniectomy. Acta Neurochir. 154, 1555-1561.

7. Nijboer, J.M.M., van der Naalt, J., and Duis, H.-J. (2010). Patients beyond salvation? Various categories of trauma patients with a minimal Glasgow Coma Score. Injury 41, 52-57.

8. Seelig, J.M., Becker, D.P., Miller, J.D., Greenberg, R.P., Ward, J.D., and Choi, S.C. (1981). Traumatic acute subdural hematoma: major mortality reduction in comatose patients treated within four hours. $\mathrm{N}$. Engl. J. Med. 304, 1511-1518.

9. Dent, D.L., Croce, M.A., Menke, P.G., Young, B.H., Hinson, M.S., Kudsk, K.A., Minard, G., Pritchard, F.E., Robertson, J.T., and Fabian, T.C. (1995). Prognostic factors after acute subdural hematoma. J. Trauma 39, 36-43.

10. Mathew, P., Oluoch-Olunya, D.L., Condon, B.R., and Bullock, R. (1993). Acute subdural haematoma in the conscious patient: outcome with initial non-operative management. Acta Neurochir. 121, 100108.

11. Servadei, F., Nasi, M.T., Cremonini, A.M., Giuliani, G., Cenni, P., and Nanni, A. (1998). Importance of a reliable admission Glasgow Coma Scale score for determining the need for evacuation of posttraumatic subdural hematomas: a prospective study of 65 patients. J. Trauma 44 , 868-873.

12. Bell, R.S., Mossop, C.M., Dirks, M.S., Stephens, F.L., Mulligan, L., Ecker, R., Neal, C.J., Kumar, A., Tigno, T., and Armonda, R.A
(2010). Early decompressive craniectomy for severe penetrating and closed head injury during wartime. Neurosurg. Focus 28, E1.

13. Guerra, W.K., Gaab, M.R., Dietz, H., Mueller, J.U., Piek, J., and Fritsch, M.J. (1999). Surgical decompression for traumatic brain swelling: indications and results. J. Neurosurg. 90, 187-196.

14. Yang, X.F., Wen, L., Shen, F., Li, G., Lou, R., Liu, W.G., and Zhan, R.Y. (2008). Surgical complications secondary to decompressive craniectomy in patients with a head injury: a series of 108 consecutive cases. Acta Neurochir. 150, 1241-1248.

15. Cooper, D.J., Rosenfeld, J.V., Murray, L., Arabi, Y.M., Davies, A.R., D’Urso, P., Kossmann, T., Ponsford, J., Seppelt, I., Reilly, P., and Wolfe, R. (2011). Decompressive craniectomy in diffuse traumatic brain injury. N. Engl. J. Med. 364, 1493-1502.

16. Cooper, P.R., Rovit, R.L., and Ransohoff, J. (1976). Hemicraniectomy in the treatment of acute subdural hematoma: a re-appraisal. Surg. Neurol. 5, 25-28.

17. Honeybul, S., Janzen, C., Kruger, K., and Ho, K.M. (2013). Decompressive craniectomy for severe traumatic brain injury: is life worth living? J. Neurosurg. 119, 1566-1575.

18. Servadei, F., Compagnone, C., and Sahuquillo, J. (2007). The role of surgery in traumatic brain injury. Curr. Opin. Crit. Care 13, 163-168.

19. Leitgeb, J., Mauritz, W., Brazinova, A., Janciak, I., Majdan, M., Wilbacher, I., and Rusnak, M. (2012). Outcome after severe brain trauma due to acute subdural hematoma. J. Neurosurg. 117, 324-333.

20. Narayan, R.K., Michel, M.E., Ansell, B., Baethmann, A., Biegon, A., Bracken, M.B., Bullock, M.R., Choi, S.C., Clifton, G.L., Contant, C.F., Coplin, W.M., Dietrich, W.D., Ghajar, J., Grady, S.M., Grossman, R.G., Hall, E.D., Heetderks, W., Hovda, D.A., Jallo, J., Katz, R.L., Knoller, N., Kochanek, P.M., Maas, A.I., Majde, J., Marion, D.W., Marmarou, A., Marshall, L.F., McIntosh, T.K., Miller, E., Mohberg, N., Muizelaar, J.P., Pitts, L.H., Quinn, P., Riesenfeld, G., Robertson, C.S., Strauss, K.I., Teasdale, G., Temkin, N., Tuma, R., Wade, C., Walker, M.D., Weinrich, M., Whyte, J., Wilberger, J., Young, A.B., and Yurkewicz, L. (2002). Clinical trials in head injury. J. Neurotrauma 19, 503-557.

21. Roozenbeek, B., Lingsma, H.F., and Maas, A.I. (2012). New considerations in the design of clinical trials for traumatic brain injury. Clin. Investig. 2, 153-162.

22. Roozenbeek, B., Maas, A.I.R., and Menon, D.K. (2013). Changing patterns in the epidemiology of traumatic brain injury. Nat. Rev. Neurol. 9, 231-236.

23. Stocchetti, N., Paternò, R., Citerio, G., Beretta, L., and Colombo, A. (2012). Traumatic brain injury in an aging population. J. Neurotrauma $29,1119-1125$

24. Steinbüchel, von, N., Wilson, L., Gibbons, H., Hawthorne, G., Höfer, S., Schmidt, S., Bullinger, M., Maas, A., Neugebauer, E., Powell, J., Wild, Von, K., Zitnay, G., Bakx, W., Christensen, A.-L., Koskinen, S., Sarajuuri, J., Formisano, R., Sasse, N., and Truelle, J.-L. (2010). Quality of Life after Brain Injury (QOLIBRI): scale development and metric properties. J. Neurotrauma 27, 1167-1185.

25. Steinbuechel, von, N., Petersen, C., and Bullinger, M. (2005). Assessment of health-related quality of life in persons after traumatic brain injury-development of the QOLIBRI, a specific measure. Acta Neurochir. Suppl. 93, 43-49.

26. Van Essen, T.A., De Ruiter, G.C.W., Peul, W.C. (2014). Factors of influence on surgical decision making and outcome in patients with acute subdural hematoma: a retrospective study of 109 patients with evaluation of quality of life. Paper presented at the 11th Symposium of the International Neurotrauma Society March 19-23, 2014 Budapest, Hungary. J. Neurotrauma 31:A1-A73, 2014.

27. Ubel, P.A., Loewenstein, G., Schwarz, N., and Smith, D. (2005). Misimagining the unimaginable: the disability paradox and health care decision making. Health Psychol. 24, S57-62.

28. Kahneman, D. (2011). Thinking, Fast and Slow. Macmillan: New York.

29. Kelly, M.L., Sulmasy, D.P., and Weil, R.J. (2013). Spontaneous intracerebral hemorrhage and the challenge of surgical decision making: a review. Neurosurg. Focus 34, E1.

30. Rayan, N., Barnes, S., Fleming, N., Kudyakov, R., Ballard, D., Gentilello, L.M., and Shafi, S. (2012). Barriers to compliance with evidence-based care in trauma. J. Trauma Acute Care Surg. 72, 58593.

31. Kolias, A.G., Belli, A., Li, L.M., Timofeev, I., Corteen, E.A., Santarius, T., Menon, D.K., Pickard, J.D., Kirkpatrick, P.J., and Hutchinson, P.J. (2012). Primary decompressive craniectomy for acute 
subdural haematomas: results of an international survey. Acta Neurochir. 154, 1563-1565.

32. Murray, G.D., Teasdale, G.M., Braakman, R., Cohadon, F., Dearden, M., Iannotti, F., Karimi, A., Lapierre, F., Maas, A., Ohman, J., Persson, L., Servadei, F., Stocchetti, N., Trojanowski, T., and Unterberg, A. (1999). The European Brain Injury Consortium survey of head injuries. Acta Neurochir. 141, 223-236.

33. Bulger, E.M., Nathens, A.B., Rivara, F.P., Moore, M., MacKenzie, E.J., and Jurkovich, G.J. (2002). Management of severe head injury: institutional variations in care and effect on outcome. Crit. Care Med. 30, 1870-1876.

34. Clifton, G.L., Choi, S.C., Miller, E.R., Levin, H.S., Smith, K.R.J., Muizelaar, J.P., Wagner, F.C.J., Marion, D.W., and Luerssen, T.G. (2001). Intercenter variance in clinical trials of head trauma-experience of the National Acute Brain Injury Study: Hypothermia. J. Neurosurg. 95, 751-755.

35. Ghajar, J., Hariri, R.J., Narayan, R.K., Iacono, L.A., Firlik, K., and Patterson, R.H. (1995). Survey of critical care management of comatose, head-injured patients in the United States. Crit. Care Med. 23, $560-567$.

36. Hukkelhoven, C.W.P.M., Steyerberg, E.W., Farace, E., Habbema, J.D.F., Marshall, L.F., and Maas, A.I.R. (2002). Regional differences in patient characteristics, case management, and outcomes in traumatic brain injury: experience from the tirilazad trials. J. Neurosurg. 97, 549-557.

37. Jennett, B., Teasdale, G., Galbraith, S., Pickard, J., Grant, H., Braakman, R., Avezaat, C., Maas, A., Minderhoud, J., Vecht, C.J., Heiden, J., Small, R., Caton, W., and Kurze, T. (1977). Severe head injuries in three countries. J. Neurol. Neurosurg. Psychiatry 40, 291-298.

38. Stocchetti, N., Penny, K., Dearden, M., Braakman, R., Cohadon, F.X.O., Iannotti, F., Lapierre, F.X.O., Karimi, A., Maas, A., Murray, G., Ohman, J., Persson, L., Servadei, F., Teasdale, G., Trojanowski, T., and Unterberg, A. European Brain Injury Consortium (2001). Intensive care management of head-injured patients in Europe: a survey from the European Brain Injury Consortium. Intensive Care Med. 27, $400-406$.
39. Brattheim, B.J., Eikemo, T.A., Altreuther, M., Landmark, A.D., and Faxvaag, A. (2012). Regional disparities in incidence, handling and outcomes of patients with symptomatic and ruptured abdominal aortic aneurysms in Norway. Eur. J. Vasc. Endovasc. Surg. 44, 267-272.

40. Gregson, B.A., and Mendelow, A.D. (2003). International variations in surgical practice for spontaneous intracerebral hemorrhage. Stroke $34,2593-2597$.

41. Compagnone, C., Murray, G.D., Teasdale, G.M., Maas, A.I.R., Esposito, D., Princi, P., D Avella, D., and Servadei, F. (2005). The management of patients with intradural post-traumatic mass lesions: a multicenter survey of current approaches to surgical management in 729 patients coordinated by the European Brain Injury Consortium. Neurosurgery $57,1183-1192$.

42. Mendelow, A.D., Gregson, B.A., Rowan, E.N., Francis, R., McColl, E., McNamee, P., Chambers, I., Unterberg, A.W., Boyers, D., and Mitchell, P. (2015). Early surgery versus initial conservative treatment in patients with traumatic intracerebral haemorrhage [STITCH(Trauma)]: the first randomised trial. J. Neurotrauma

43. Lingsma, H.F., Roozenbeek, B., Li, B., Lu, J., Weir, J., Butcher, I., Marmarou, A., Murray, G.D., Maas, A.I.R., and Steyerberg, E.W. (2011). Large between-center differences in outcome after moderate and severe traumatic brain injury in the International Mission on Prognosis and Clinical Trial Design in Traumatic Brain Injury (IMPACT) study. Neurosurgery 68, 601-608.

44. Timmons, S.D., and Toms, S.A. (2012). Comparative effectiveness research in neurotrauma. Neurosurg. Focus 33, E3.

Address correspondence to: Thomas A. van Essen, $M D$ Albinusdreef 2, J-11-R-83 2333 ZA, Leiden The Netherlands

E-mail: T.A.van_Essen@lumc.nl 


\section{This article has been cited by:}

1. Nasim Ahmed, Patricia Greenberg, SeungHoon Shin. 2020. Mortality Outcome of Emergency Decompressive Craniectomy and Craniotomy in the Management of Acute Subdural Hematoma: A National Data Analysis. The American Surgeon 71, 000313482095146. [Crossref]

2. Guoyi Gao, Xiang Wu, Junfeng Feng, Jiyuan Hui, Qing Mao, Fiona Lecky, Hester Lingsma, Andrew I R Maas, Jiyao Jiang. 2020. Clinical characteristics and outcomes in patients with traumatic brain injury in China: a prospective, multicentre, longitudinal, observational study. The Lancet Neurology 19:8, 670-677. [Crossref]

3. David Robinson, Jane C. Khoury, Dawn Kleindorfer. 2020. Regional Variation in the Management of Nontraumatic Subdural Hematomas Across the United States. World Neurosurgery 135, e418-e423. [Crossref]

4. Wenjia Zhang, Zhongqiao Qin, Kecong Xian, Shuhong Tang. 2020. Assessment of plasma homocysteine levels in patients with craniocerebral injury and prognosis. Journal of International Medical Research 48:3, 030006051988220. [Crossref]

5. Thomas A. Van Essen, Victor Volovici, Maryse C. Cnossen, Angelos Kolias, Iris Ceyisakar, Daan Nieboer, Lianne D. Peppel, Majanka Heijenbrok-Kal, Gerard Ribbers, David Menon, Peter Hutchinson, Bart Depreitere, Godard C. W. de Ruiter, Hester F. Lingsma, Ewout W. Steyerberg, Andrew I Maas, Wilco C. Peul. 2019. Comparative effectiveness of surgery in traumatic acute subdural and intracerebral haematoma: study protocol for a prospective observational study within CENTER-TBI and NetQuRe. BMJ Open 9:10, e033513. [Crossref]

6. Jeroen T. J. M. van Dijck, Mark D. Dijkman, Robbin H. Ophuis, Godard C. W. de Ruiter, Wilco C. Peul, Suzanne Polinder. 2019. In-hospital costs after severe traumatic brain injury: A systematic review and quality assessment. PLOS ONE 14:5, e0216743. [Crossref]

7. Jeroen T. J. M. van Dijck, Thomas A. van Essen, Mark D. Dijkman, Cassidy Q. B. Mostert, Suzanne Polinder, Wilco C. Peul, Godard C. W. de Ruiter. 2019. Functional and patient-reported outcome versus in-hospital costs after traumatic acute subdural hematoma (t-ASDH): a neurosurgical paradox?. Acta Neurochirurgica 161:5, 875-884. [Crossref]

8. van Essen Thomas A., Dijkman Mark D., Cnossen Maryse C., Moudrous Walid, Ardon Hilko, Schoonman Guus G., Steyerberg Ewout W., Peul Wilco C., Lingsma Hester F., de Ruiter Godard C.W.. 2019. Comparative Effectiveness of Surgery for Traumatic Acute Subdural Hematoma in an Aging Population. Journal of Neurotrauma 36:7, 1184-1191. [Abstract] [Full Text] [PDF] [PDF Plus] [Supplementary Material]

9. Thomas A. van Essen, Hugo F. den Boogert, Maryse C. Cnossen, Godard C. W. de Ruiter, Iain Haitsma, Suzanne Polinder, Ewout W. Steyerberg, David Menon, Andrew I. R. Maas, Hester F. Lingsma, Wilco C. Peul. 2019. Variation in neurosurgical management of traumatic brain injury: a survey in 68 centers participating in the CENTER-TBI study. Acta Neurochirurgica 161:3, 435-449. [Crossref]

10. Angelos G. Kolias, Edoardo Viaroli, Andres M. Rubiano, Hadie Adams, Tariq Khan, Deepak Gupta, Amos Adeleye, Corrado Iaccarino, Franco Servadei, Bhagavatula Indira Devi, Peter J. Hutchinson. 2018. The Current Status of Decompressive Craniectomy in Traumatic Brain Injury. Current Trauma Reports 4:4, 326-332. [Crossref]

11. Alessandro Orlando, A. Stewart Levy, Benjamin A. Rubin, Allen Tanner, Matthew M. Carrick, Mark Lieser, David Hamilton, Charles W. Mains, David Bar-Or. 2018. Isolated subdural hematomas in mild traumatic brain injury. Part 2: a preliminary clinical decision support tool for neurosurgical intervention. Journal of Neurosurgery 336, 1-8. [Crossref]

12. Yu Deok Won, Min Kyun Na, Je-Il Ryu, Jin-Hwan Cheong, Jae-Min Kim, Choong-Hyun Kim, Myung-Hoon Han. 2018. Radiologic Factors Predicting Deterioration of Mental Status in Patients with Acute Traumatic Subdural Hematoma. World Neurosurgery 111, e120-e134. [Crossref]

13. Maryse C. Cnossen, Jilske A. Huijben, Mathieu van der Jagt, Victor Volovici, Thomas van Essen, Suzanne Polinder, David Nelson, Ari Ercole, Nino Stocchetti, Giuseppe Citerio, Wilco C. Peul, Andrew I. R. Maas, David Menon, Ewout W. Steyerberg, Hester F. Lingsma. 2017. Variation in monitoring and treatment policies for intracranial hypertension in traumatic brain injury: a survey in 66 neurotrauma centers participating in the CENTER-TBI study. Critical Care 21:1. . [Crossref]

14. Andrew I R Maas, David K Menon, P David Adelson, Nada Andelic, Michael J Bell, Antonio Belli, Peter Bragge, Alexandra Brazinova, András Büki, Randall M Chesnut, Giuseppe Citerio, Mark Coburn, D Jamie Cooper, A Tamara Crowder, Endre Czeiter, Marek Czosnyka, Ramon Diaz-Arrastia, Jens P Dreier, Ann-Christine Duhaime, Ari Ercole, Thomas A van Essen, Valery L Feigin, Guoyi Gao, Joseph Giacino, Laura E Gonzalez-Lara, Russell L Gruen, Deepak Gupta, Jed A Hartings, Sean Hill, Ji-yao Jiang, Naomi Ketharanathan, Erwin J O Kompanje, Linda Lanyon, Steven Laureys, Fiona Lecky, Harvey Levin, Hester F Lingsma, Marc Maegele, Marek Majdan, Geoffrey Manley, Jill Marsteller, Luciana Mascia, Charles McFadyen, Stefania Mondello, Virginia Newcombe, Aarno Palotie, Paul M Parizel, Wilco Peul, James Piercy, Suzanne Polinder, Louis Puybasset, Todd E Rasmussen, Rolf Rossaint, Peter Smielewski, Jeannette Söderberg, Simon J Stanworth, Murray B Stein, Nicole von Steinbüchel, William Stewart, Ewout W Steyerberg, Nino Stocchetti, Anneliese Synnot, Braden Te Ao, Olli Tenovuo, Alice Theadom, Dick 
Tibboel, Walter Videtta, Kevin K W Wang, W Huw Williams, Lindsay Wilson, Kristine Yaffe, Hadie Adams, Vanni Agnoletti, Judith Allanson, Krisztina Amrein, Norberto Andaluz, Audny Anke, Anna Antoni, Arjan Bastiaan van As, Gérard Audibert, Antun Azaševac, Philippe Azouvi, Maria Luisa Azzolini, Camelia Baciu, Rafael Badenes, Karen M Barlow, Ronald Bartels, Ursula Bauerfeind, Miriam Beauchamp, Darcy Beer, Ronny Beer, Francisco Javier Belda, Bo-Michael Bellander, Rémy Bellier, Habib Benali, Thierry Benard, Valzerda Beqiri, Luigi Beretta, Francis Bernard, Guido Bertolini, Federico Bilotta, Morten Blaabjerg, Hugo den Boogert, Kathy Boutis, Pierre Bouzat, Brian Brooks, Camilla Brorsson, Monika Bullinger, Emma Burns, Emiliana Calappi, Peter Cameron, Elsa Carise, Ana M Castaño-León, Francesco Causin, Giorgio Chevallard, Arturo Chieregato, Brian Christie, Maryse Cnossen, Jonathan Coles, Johnny Collett, Francesco Della Corte, William Craig, Gabor Csato, Akos Csomos, Nicola Curry, Claire Dahyot-Fizelier, Helen Dawes, Carol DeMatteo, Bart Depreitere, Deborah Dewey, Jeroen van Dijck, Đula Đilvesi, Diederik Dippel, Kemal Dizdarevic, Emma Donoghue, Or Duek, Guy-Loup Dulière, Adelaida Dzeko, George Eapen, Carolyn A Emery, Shane English, Patrick Esser, Erzsébet Ezer, Martin Fabricius, Junfeng Feng, Dean Fergusson, Anthony Figaji, Joanne Fleming, Kelly Foks, Gilles Francony, Stephen Freedman, Ulderico Freo, Shirin K Frisvold, Isabelle Gagnon, Damien Galanaud, Dashiell Gantner, Benoit Giraud, Ben Glocker, Jagoš Golubovic, Pedro A Gómez López, Wayne A Gordon, Primoz Gradisek, Jocelyn Gravel, Donald Griesdale, Francesca Grossi, Juanita A Haagsma, Asta Kristine Håberg, Iain Haitsma, Wim Van Hecke, Raimund Helbok, Eirik Helseth, Caroline van Heugten, Cornelia Hoedemaekers, Stefan Höfer, Lindsay Horton, Jiyuan Hui, Jilske Antonia Huijben, Peter J Hutchinson, Bram Jacobs, Mathieu van der Jagt, Stefan Jankowski, Koen Janssens, Bojan Jelaca, Kelly M Jones, Konstantinos Kamnitsas, Rafael Kaps, Mladen Karan, Ari Katila, Kirsi-Maija Kaukonen, Véronique De Keyser, Riku Kivisaari, Angelos G Kolias, Bálint Kolumbán, Ksenija Kolundžija, Daniel Kondziella, Lars-Owe Koskinen, Noémi Kovács, Andreas Kramer, Demitri Kutsogiannis, Theodoros Kyprianou, Alfonso Lagares, François Lamontagne, Roberto Latini, François Lauzier, Isaac Lazar, Christian Ledig, Rolf Lefering, Valerie Legrand, Leon Levi, Roger Lightfoot, Angels Lozano, Stephen MacDonald, Sebastian Major, Alex Manara, Pauline Manhes, Hugues Maréchal, Costanza Martino, Alessandro Masala, Serge Masson, Julia Mattern, Bradford McFadyen, Catherine McMahon, Maureen Meade, Béla Melegh, Tomas Menovsky, Lynne Moore, Marta Morgado Correia, Maria Cristina Morganti-Kossmann, Holger Muehlan, Pratik Mukherjee, Lynnette Murray, Joukje van der Naalt, Ancuta Negru, David Nelson, Daan Nieboer, Quentin Noirhomme, József Nyirádi, Mauro Oddo, David O Okonkwo, Annemarie W Oldenbeuving, Fabrizio Ortolano, Martin Osmond, Jean-François Payen, Vincent Perlbarg, Paolo Persona, Nicolas Pichon, Anna Piippo-Karjalainen, Sébastien Pili-Floury, Matti Pirinen, Horia Ple, Maria Antonia Poca, Jussi Posti, Dominique Van Praag, Alain Ptito, Andreea Radoi, Arminas Ragauskas, Rahul Raj, Ruben G L Real, Nick Reed, Jonathan Rhodes, Claudia Robertson, Saulius Rocka, Cecilie Røe, Olav Røise, Gerwin Roks, Jonathan Rosand, Jeffrey V Rosenfeld, Christina Rosenlund, Guy Rosenthal, Sandra Rossi, Daniel Rueckert, Godard C W de Ruiter, Marco Sacchi, Barbara J Sahakian, Juan Sahuquillo, Oliver Sakowitz, Gerardo Salvato, Renán Sánchez-Porras, János Sándor, Grinder Sangha, Nadine Schäfer, Silke Schmidt, Kathryn J Schneider, David Schnyer, Herbert Schöhl, Guus G Schoonman, Rico Frederik Schou, Özcan Sir, Toril Skandsen, Dirk Smeets, Abayomi Sorinola, Emmanuel Stamatakis, Ana Stevanovic, Robert D Stevens, Nina Sundström, Fabio Silvio Taccone, Riikka Takala, Päivi Tanskanen, Mark Steven Taylor, Ralph Telgmann, Nancy Temkin, Guido Teodorani, Matt Thomas, Christos M Tolias, Tony Trapani, Alexis Turgeon, Peter Vajkoczy, Alex B Valadka, Egils Valeinis, Shirley Vallance, Zoltán Vámos, Alessia Vargiolu, Emmanuel Vega, Jan Verheyden, Anne Vik, Rimantas Vilcinis, Carmen Vleggeert-Lankamp, Lidia Vogt, Victor Volovici, Daphne C Voormolen, Peter Vulekovic, Thijs Vande Vyvere, Julia Van Waesberghe, Lars Wessels, Eno Wildschut, Guy Williams, Maren K L Winkler, Stefan Wolf, Gordon Wood, Nektaria Xirouchaki, Alexander Younsi, Menashe Zaaroor, Veronika Zelinkova, Roger Zemek, Fabrizio Zumbo. 2017. Traumatic brain injury: integrated approaches to improve prevention, clinical care, and research. The Lancet Neurology 16:12, 987-1048. [Crossref] 